\title{
Rapid data collection in Kenya's urban informal settlements informs national COVID-19 response
}

Population Council

Follow this and additional works at: https://knowledgecommons.popcouncil.org/

series_newsletters_researchimpact

How does access to this work benefit you? Let us know!

\section{Recommended Citation}

"Rapid data collection in Kenya's urban informal settlements informs national COVID-19 response," Research Utilization and Impact Brief. Washington, DC: Population Council, 2021. 


\section{Rapid Data Collection in Kenya's Urban Informal Settlements Informs National COVID-19 Response}

Rapid, localized research by the Population Council has supported a data-driven national COVID-19 response in Kenya, including informing evidence-based guidance and strategies; reinforcing the need for gender and youth-responsive policies; and strengthening close collaboration among government, researchers, and implementing partners.

\section{INTRODUCTION}

Given the swift onset of COVID-19, many countries lacked relevant data needed to inform effective, equitable, and coordinated responses. In the early days of the global pandemic, Population Council's Kenya team partnered with the Ministry of Health $(\mathrm{MOH})$ to understand the government's data needs, which led to four novel knowledge, attitude, and practices (KAP) surveys focused on informal settlements in Nairobi.

The Council's existing relationships with communities and the Government of Kenya (GoK) allowed researchers to quickly engage cohorts from other ongoing research, including Adolescent Girls Initiative-Kenya, NISITU, Nia, and DREAMS. These projects work primarily with adolescent girls, as well as their partners, families, and communities, facilitating data collection with populations disproportionately affected by COVID-19.

\section{RESEARCH IMPACTS}

In Kenya, Council-generated data on COVID-19 has been used to inform public messaging, support policy action and create national guidance in response to evolving needs, and reinforce collaboration and information sharing through a partner dashboard. Throughout this

\section{KEY FINDINGS ACROSS KAP SURVEYS}
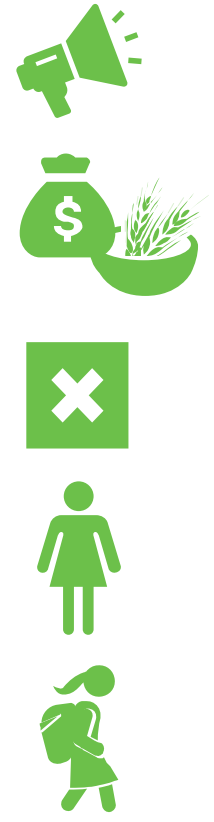

Information Channels: High

trust in $\mathrm{CHWs}$

Challenges: Food scarcity, missed health services, loss of income, heightened experiences of violence

Home Based Isolation/Care: Low feasibility

Gender Lens: Women disproportionately impacted by quarantine

Adolescents: Gender divide in technology access, mixed methods of learning, need for mental health supports process, Council staff have participated in and provided regular updates to the MOH's National Emergency Response Committee (NERC) through the Community Engagement Subcommittee, as well as the Executive Office of the President's Policy and Strategy Unit.

Informing Public Messaging: Findings on COVID-19-related knowledge gaps and current information delivery channels informed the Ministry of Health's development of public 
education campaigns. Repeated rounds of data collection provided timely evidence that enabled the $\mathrm{MOH}$ to tailor messaging as the epidemic and public knowledge, attitudes and practices quickly evolved. In addition to informing updated $\mathrm{MOH}$ public messages, the first round of data collection in March 2020 highlighted a high level of trust in community health workers (CHWs) and reinforced their role as critical COVID-19 public health educators.

Supporting Policy Action: Identifying some of the key challenges faced in informal settlements, especially among women and adolescents, has assisted the National Emergency Response Committee (NERC) to monitor the individual and household-level effects of COVID-19. Concerned that people would forgo testing because of the economic burden of a positive result and resulting mandatory quarantine, Council research informed

\section{EVIDENCE USE BY DEVELOPMENT PARTNERS}

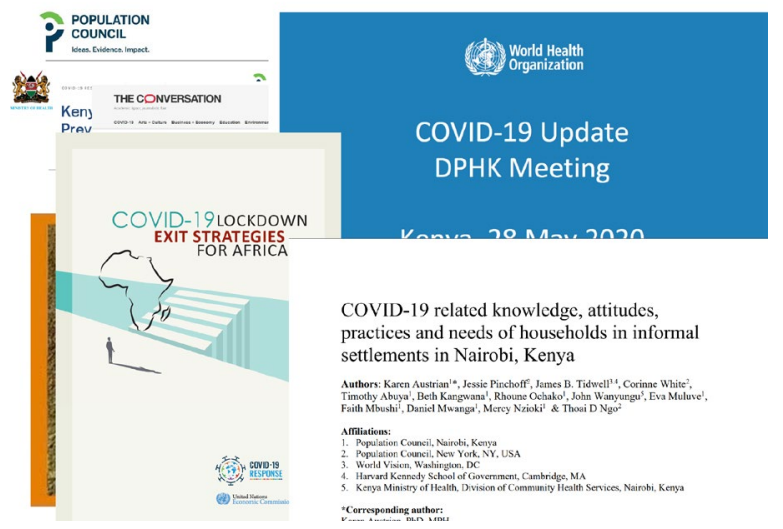

Rapid dissemination of data during the initial weeks and months of the COVID-19 epidemic led to study findings being widely cited and used, including in presentations and publications by:

- Multilaterals: The Kenyan Representative to the World Health Organization (WHO); and the United Nations Economic Commission for Africa.

- Bilaterals and partners: The UK Department for International Development (DFID); US Agency for International Development (USAID) and Centers for Disease Control (CDC); and their nongovernmental partners. government efforts to provide assistance for those who tested positive.

Council-generated evidence was also used to inform ongoing updates to COVID-19 policies and guidelines. Questions related to the feasibility of home-based quarantine demonstrated that this approach was impossible for many living in informal settlements, which led to updated guidance on home-based isolation and care.

Reinforcing Partner Collaboration: Beyond collection and dissemination of data on COVID-19 in Nairobi's informal settlements, the Council's team also led the development of a community dashboard for partners working throughout Kenya to consolidate their experiences and activities across all 47 counties. This dashboard has played a critical role in supporting the government to track in real-time what is happening across the country to address COVID-19. The dashboard is updated on a weekly basis by health workers tracking myths and misconceptions by county, as well as lessons and challenges from the pandemic.

\section{LOOKING FORWARD}

Meeting the need for timely and context-specific data, the Council continues to contribute to Kenya's COVID-19 response through the government and its partners. Over the course of four surveys in 2020, the focus and scope of questions has evolved, and there is interest in continuing this work to inform both short and long-term COVID-19 response efforts. For instance, Round 4 data collection extended beyond the informal settlements of Nairobi to Kisumu and cohorts in more rural Kilifi and Wajir counties, including adolescents and adults in each household. The focus of the surveys has also expanded to better understand the social, health, education, and economic impacts of COVID-19.

Future research will explore the impact of COVID-19 on adolescents' relationships, and data collection will include urban and rural sites in Nairobi, Kisumu, Kilifi, and Wajir counties. Also, 
policymakers are particularly keen to understand the longer-term effects of COVID-19 and quarantine on livelihoods, school re-enrollment, pregnancy, and child marriage, which the Population Council will continue to track.

The Population Council's Kenya team is working with the Office of the President to conceptualize, draft and disseminate a roadmap to ensure adolescent girls' healthy transitions to adulthood throughout the COVID-19 recovery period. Leveraging preexisting knowledge of "what works" for adolescent girls together with analysis of data collected in ongoing COVID-19 surveys with adolescents, recommendations for future investments supporting this population will be co-developed with the Office of the President.

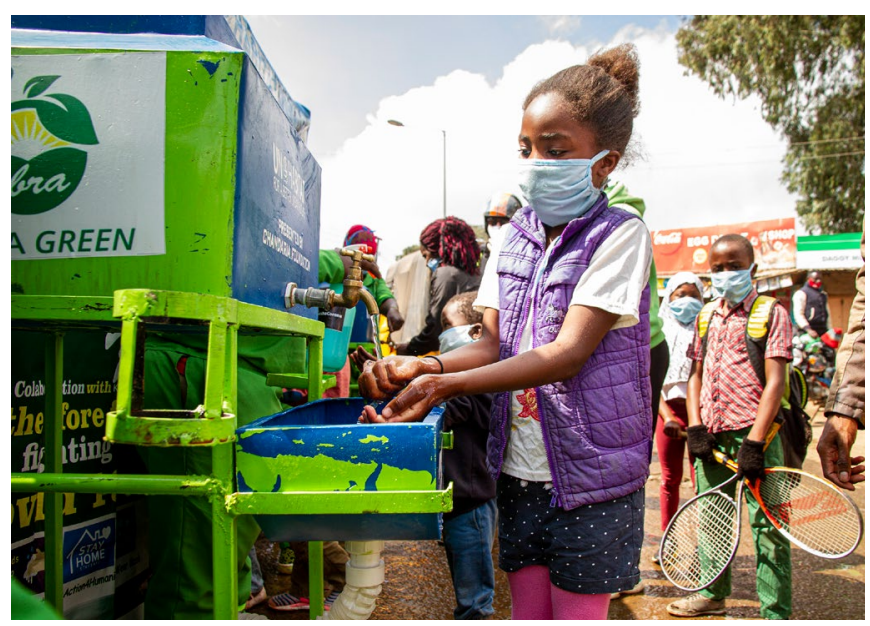

Photo: (c) UN-Habitat/Kirsten Milhahn

For more information, please visit Responding to the COVID-19 Pandemic

\section{SELECTED RESOURCES}

\begin{tabular}{|c|c|}
\hline $\begin{array}{l}\text { Journal } \\
\text { Articles }\end{array}$ & $\begin{array}{l}\text { - The impact of COVID-19 control measures on social contacts and transmission in Kenyan } \\
\text { informal settlements } \\
\text { - } \quad \text { Pre-pandemic Influences on Kenyan Girls' Transitions to Adulthood during COVID-19 } \\
\text { - COVID-19 Related Knowledge, Attitudes, Practices and Needs of Households in Informal } \\
\text { Settlements in Nairobi, Kenya }\end{array}$ \\
\hline Briefs & $\begin{array}{l}\text { - Round 1:Kenya: COVID-19 Knowledge, Attitudes \& Practices } \\
\text { - Round 2: Kenya: COVID-19 Knowledge, Attitudes, Practices \& Needs } \\
\text { - Round 3: Kenya: COVID-19 Perceptions, Prevention Practices, and Impact } \\
\text { - Round 4: } \\
\text { - Kenya: Adolescent COVID-19 Perceptions, Prevention Practices and Impact } \\
\text { - Kenya: Gender effects of COVID-19 } \\
\text { - Kenya: COVID-19 Perceptions, Stigma and Impact }\end{array}$ \\
\hline Other & $\begin{array}{l}\text { - Dataset: COVID-19-related knowledge, attitudes, and practices in urban slums in } \\
\text { - Nairobi, Kenya } \\
\text { - Partner Dashboard: COVID-19 Community Engagement Monitoring Dashboard } \\
\text { - Webinar: The Impact of COVID-19 on Urban Informal Settlements: Lessons from Kenya }\end{array}$ \\
\hline
\end{tabular}

The Population Council collaborates with program implementers, policymakers, researchers, and funding partners to advance evidence-based solutions to critical health and development challenges. The Council's research impact briefs feature recent highlights of our ongoing work to ensure evidence is translated into meaningful actions at community, national, regional, and global levels to improve lives around the world.

Recommended citation: "Responsive COVID-19 Data Collection in Kenya's Urban Informal Settlements Informs National Response Efforts," Research Utilization and Impact Brief. Washington, DC: Population Council, 2021. 